\title{
The Wind-Induced Vibration Response for Tower Crane Based on Virtual Excitation Method
}

\author{
Hongqi Jiang* and Shuncai Li \\ School of Mechanical \& Electrical Engineering, Jiangsu Normal University, Xuzhou, Jiangsu, 221116, P.R. China
}

\begin{abstract}
The dynamics of Tower Crane is complicated by wind excitation which complicates the wind-induced vibration response analysis. The random wind-induced response analysis of tower crane is presented based on finite element method and virtual excitation method. The pulsating wind loads change into multiple-point correlation stationary excitation. This paper uses Davenport's wind speed spectrum which does not change with height, and considers multiplepoint correlation of wind-induction. The tower crane was employed as a numerical example; the response spectra and Mean Square Root (RMS) of the tower crane were obtained by wind-induced vibration. The results indicate that the vibration of the tower crane showed a greater response in low frequency with the One-third Octave acceleration RMS being lower. Finally, the influences of the wind-induced vibration on comfort were analyzed.
\end{abstract}

Keywords: Tower Crane, Wind-induced response, Virtual excitation method, Pseudo-Excitation.

\section{INTRODUCTION}

As a kind of engineering machinery and equipment, the tower crane is widely used in construction. The structural stability and security are one of the key technologies of tower crane research. With the increased construction of tall buildings, operation difficulty increases due to the increase in the height of the tower crane. As the tower arm slenderness ratio becomes larger, the wind load effect becomes more apparent. As the wind loading produces larger deformation and vibration [1-3], it can have serious impact on the safety of the tower crane and operational personnel.

Natural wind exhibits random fluctuations when it flows over land especially in the built environment full of obstacles. It is generally believed that natural wind is composed of average wind and fluctuating wind [4], and the speed of the wind has an average component and a pulsating component. Therefore, under the effect of natural wind, the load structure of wind is composed of two aspects: one is the average calm load under the action of the wind; and the second is fluctuating load under the action of random pulse. The load structure caused by static deformation can be obtained through static analysis of the structure; whereas fluctuating wind component causes induced vibration of the structure. Continuous vibration can cause structure fatigue damage and also result in discomfort of the workers.

In conventional design, the wind load is often taken into consideration as the static force and a certain wind vibration coefficient. The calculation results cannot fully reflect the dynamic response of wind load excitation. So it is necessary to carry out the dynamic response analysis of aerial work machinery under the fluctuating wind load in order to grasp

*Address correspondence to this author at the 101 Shanghai road tongshan, Xuzhou, Jiangsu, 221116, P.R. China; Tel: +8613852482932; Fax: +86516-83500251; E-mail: jianghq@jsnu.edu.cn the dynamic performance of the structure and improve the reliability of the system design.

\section{BASIC THEORY OF PSEUDO-EXCITATION METHOD}

According to the vibration theory, under zero initial condition, the constant coefficient linear frequency response function of the system is the ratio of the input vector and the output harmonic content, namely:

$$
H(\omega)=\frac{X_{\omega}(t)}{Y_{\omega}(t)}
$$

Where, $H(\omega)$ is the frequency response function; $X_{\omega}(t)$ is the Fourier transform of $x(t) ; Y_{\omega}(t)$ is the Fourier transform of $y(t)$.

When the linear system is affected by the stationary random excitation function $F(t)$ of the spectral density $S_{F F}(\omega)$, the response of power spectrum is as given in equation $(2)[5,6]$.

$S_{X X}(\omega)=|H|^{2} S_{F F}(\omega)$

Where $\mathrm{H}$ is the frequency response function, which means when the random excitation of incentive is $e^{i \omega t}$, the corresponding harmonic response is $X(t)=H e^{i \omega t}$. If the incentive $e^{i \omega t}$ is multiplied by the constant $\sqrt{S_{F F}}$, which constructs a virtual incentive function $\tilde{F}(t)=\sqrt{S_{F F}} e^{i \omega t}$, then the corresponding virtual response is:

$\tilde{X}(t)=\sqrt{S_{F F}} H(\omega) e^{i \omega t}$ 
The actual response can be obtained from power spectral density and cross power spectrum density. The calculation formula is as follows:

$$
\begin{aligned}
& \tilde{X}^{*} \tilde{X}=|\tilde{X}|^{2}=|H|^{2} S_{F F}=S_{X X} \\
& \tilde{F}^{*} \tilde{X}=\sqrt{S_{F F}} e^{-i \omega t} \sqrt{S_{F F}} H e^{i \omega t}=S_{F F} H=S_{F X} \\
& \tilde{X}^{*} \tilde{F}=\sqrt{S_{F F}} H^{*} e^{-i \omega t} \sqrt{S_{F F}} H e^{i \omega t}=H^{*} S_{F F}=S_{X F}
\end{aligned}
$$

where $S_{X X}$ represents the actual response of the power spectral density, $S_{F X}$ represents the actual incentive and the actual response of the power spectral density, and $S_{X F}$ represents the actual response and actual incentive crosspower spectral density. If the system has more than one response, through (4) (6) type, the available power spectrum matrix can be obtained

$S_{F F}=\tilde{X}^{*} \tilde{X}^{T}, \quad S_{F X}=\tilde{F}^{*} \tilde{X}^{T}, \quad S_{X F}=\tilde{X}^{*} \tilde{F}^{T}$

where $*$ represents complex conjugate and $\mathrm{T}$ represents transpose.

\section{WIND VIBRATION RESPONSE ANALYSIS}

Fluctuating wind loads on the structure caused by vibration can be viewed as more coherent random vibration problem under stationary random excitation; the dynamic differential equation is set as (7).

$$
[M]\{\ddot{Z}(t)\}+[C]\{\dot{Z}(t)\}+[K]\{Z(t)\}=\{F(t)\}
$$

Where, $[M],[C],[K]$ represent the mass, damping and stiffness matrix of structure, respectively; $\{Z(t)\}$ represents the node displacement vector; and $\{F(t)\}$ represents the wind load vector of fluctuation.

According to the vibration mode decomposition method, the equation (7) can be rewritten according to the vibration mode $[7,8]$.

$$
\{z(t)\}=\sum_{j=1}^{q}\left\{\varphi_{j}\right\} u_{j}(t)=[\varphi]\{u(t)\}
$$

Where $\mathrm{q}$ is the selected number of vibration mode, $u_{j}$ represents the displacement, and $\varphi_{j}$ represents the vibration vector.

According to the specification, general Davenport fluctuating wind velocity spectrum is taken as the excitation spectrum; it does not change with height, since the power spectrum of its expression is:

$$
S_{f f}(n)=\frac{4 K \bar{V}_{10}^{2} x_{0}^{2}}{n\left(1+x_{0}^{2}\right)^{4 / 3}}, x_{0}=\frac{1200 n}{\bar{V}_{10}}
$$

Among them: $n=\omega / 2 \pi$ represents the pulsating wind frequency; $\bar{V}_{10}$ represents average wind speed when the height is $10 \mathrm{~m}$; and $\mathrm{K}$ is the coefficient which is related to surface roughness.

Due to the randomness of the pulse wind, a correlation function $\operatorname{coh}(\omega)$ is introduced along with consideration of the correlation among all random excitations; thus, for two points $i$ and $j$ with a spacing of $r$, their cross spectrum of horizontal pulse wind speed can be expressed as follows:

$$
S_{i j}(\omega)=\sqrt{S_{i i} S_{i j}} \operatorname{coh}(\omega)_{i j}
$$

Where

$$
\operatorname{coh}(\omega)=\exp \left(\frac{-n\left(\mathrm{C}_{\mathrm{x}} \Delta x^{2}+C_{y} \Delta y^{2}+C_{z} \Delta z^{2}\right)^{1 / 2}}{\bar{V}_{10}}\right)
$$

$\mathrm{Cx}=16, \mathrm{Cy}=\mathrm{Cz}=10$, these are spatial attenuation coefficients; $\Delta \mathrm{x}, \Delta \mathrm{y}$ and $\Delta \mathrm{z}$ are coordinate differences.

Equations (8) and (9) can form the power spectrum matrix of the node load, $\operatorname{SPP}(\omega)$. Obviously, $\operatorname{SPP}(\omega)$ is a non-negative Hermite matrix, and can be decomposed as $\mathrm{LDL}^{*}$; that is,

$$
S_{P P}(\omega)=L^{*} D L^{T}
$$

where, $\mathrm{L}$ is a lower triangular matrix with all diagonal elements being 1 ; and $\mathrm{D}$ is a real diagonal matrix.

Taking the $\mathrm{k}^{\text {th }}$-column vector of $\mathrm{L},\left\{\mathrm{L}_{\mathrm{k}}\right\}$, and the $\mathrm{k}^{\text {th }}$ diagonal element of $\mathrm{D}, \mathrm{d}_{\mathrm{k}}$, $\mathrm{n}$ pseudo-excitation vectors can be obtained as follows:

$\left\{\tilde{x}_{k}(t)\right\}=\left\{L_{k}\right\} \cdot d_{k} \cdot e^{i \omega t},(k=1,2, \cdots, n)$

Thus, the pseudo-response of the structure can be obtained as:

$$
\left\{\tilde{z}_{k}(t)\right\}=[\varphi][H][\varphi]^{T}\left\{L_{k}\right\} \sqrt{d_{k}} e^{i \omega t}
$$

where $\mathrm{H}$ is the frequency response function.

$$
H_{j}(\omega)=\frac{1}{\omega_{j}^{2}-\omega^{2}+2 i \zeta_{j} \omega_{j} \omega}
$$

where, $\omega_{\mathrm{j}}$ and $\zeta_{\mathrm{j}}$ are the $\mathrm{j}^{\text {th }}$-order self-vibration frequency and the $\mathrm{j}^{\text {th }}$-order damping ratio respectively.

The power spectrum matrix of response $\{\mathrm{z}\}$ can be obtained from Equation (4):

$$
\left[S_{z z}\right]=\sum_{k=1}^{n}\left\{\tilde{z}_{k}\right\}^{*}\left\{\tilde{z}_{k}\right\}^{T}
$$

\section{WIND VIBRATION RESPONSE ANALYSIS FOR TOWER CRANE}

Taking QTZ25 tower crane for example, the working width is $30 \mathrm{~m}$ and the lifting height is $27 \mathrm{~m}$. The tower arm and balance arm use the element simulation of beam 4 element. The pull rod can be simulated through using Link10 element. The tower crane is established as a finite element model composed of 337 nodes and 840 elements, as shown 
Table 1. The first 10 order vibration modes.

\begin{tabular}{|l|c|c|c|c|c|c|c|c|c|c|}
\hline Order Time & 1 & 2 & 3 & 4 & 5 & 6 & 7 & 8 & 9 & 10 \\
\hline Natural Frequency $(\mathbf{H z})$ & 0.25 & 0.58 & 0.65 & 1.64 & 2.56 & 3.85 & 4.04 & 5.25 & 6.86 & 7.54 \\
\hline
\end{tabular}

in Fig. (1). To obtain vibration mode, modal analysis is conducted in ANSYS and the first 10 orders of vibration modes are selected with significant influence, each of which has a damping ratio of 0.02 . The descriptions and diagrams of the first 10 orders of vibration modes are shown in Table $\mathbf{1}$.

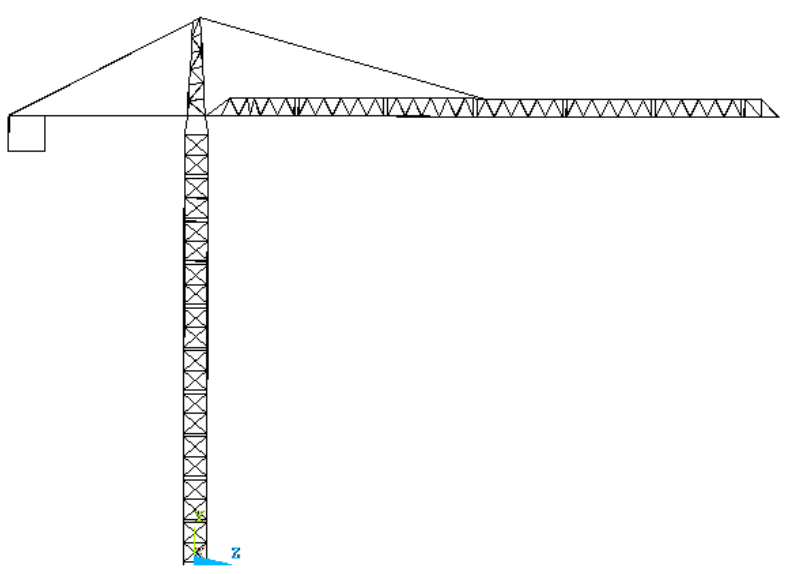

Fig. (1). Finite element model of tower crane.

The landscape coefficient was $\mathrm{K}=0.039$, the basic wind pressure was taken as $0.9 \mathrm{kN} / \mathrm{m} 2$, and Davenport pulse wind speed spectrum was selected as the standard wind speed spectrum. Using the frequency range of $0.1 \mathrm{~Hz}$ to $20 \mathrm{~Hz}$, in the MATLAB simulation program, the tower arm at the front of node 328 and location of operation room node 157, horizontal and vertical displacement, velocity and the acceleration power spectrum was obtained as shown in Figs. (2-7).

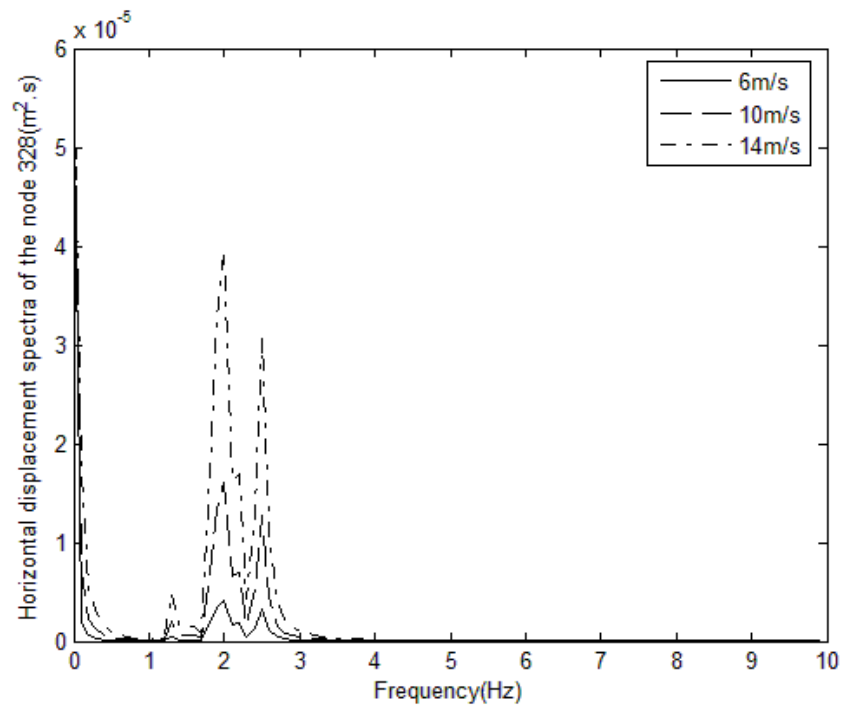

Fig. (2). Horizontal displacement spectra of Node328.

From the Figs. (2-7), it can be seen that the main response frequency is between 1 and $3 \mathrm{~Hz}$. Vibration response is obvious, and in the other frequency, the vibration is relatively small, but the natural frequency of vibration frequency and the main vibration mode frequency are nearly the same. The influence of the wind speed on the vibration was large as the amplitude has obviously increased with the increase in the wind speed.

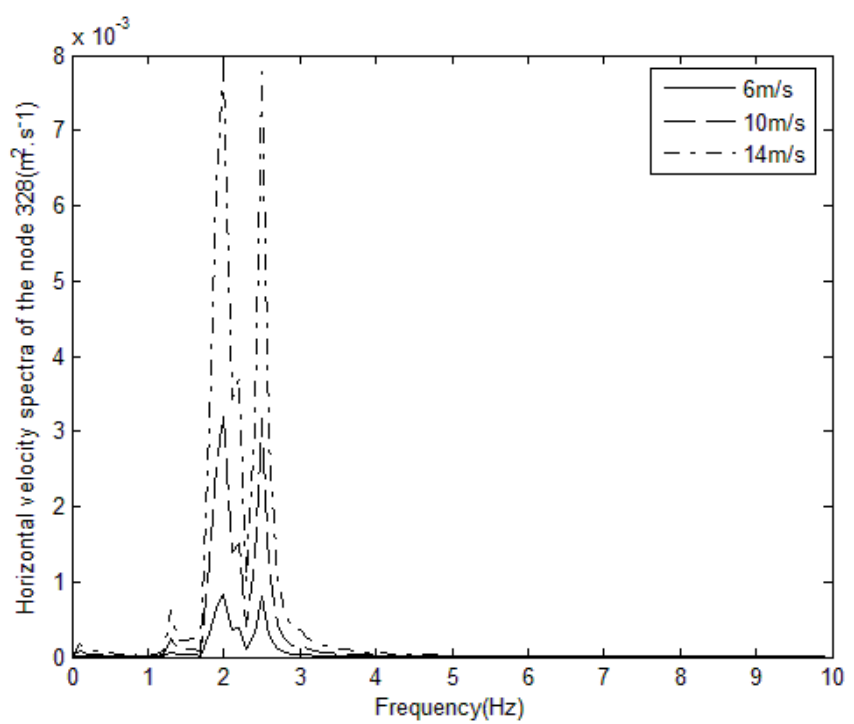

Fig. (3). Horizontal velocity spectra of node 328 .

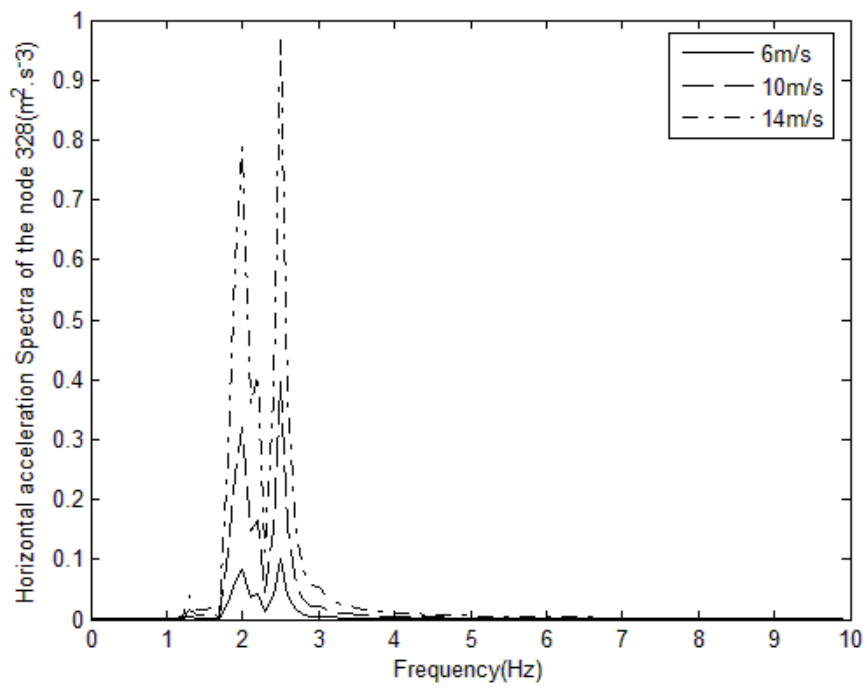

Fig. (4). Horizontal acceleration spectra of node 328.influence of the wind speed on the vibration is large as the amplitude obviously increased with the increase in the wind speed.

Recent studies have shown that $[9,10]$ sensitive frequency of human body in the vertical (up and down) fluctuation is between 4 and $8 \mathrm{~Hz}$ and the sensitive frequency of horizontal vibration (back and forth) is between 1-2 Hz. Some area of the body can produce resonance with the increased frequency. These vibrations can affect the sensitive and the comfort level of the personnel. Severe vibration response is less than $30 \mathrm{~Hz}$, the influence of vertical vibration on comfort is about $70 \%$, and horizontal 
vibration is about $12 \%$. In order to study the effect of vibration on personnel comfort, the response spectrum is calculated through pseudo-excitation method. In frequency range of 1 to $20 \mathrm{~Hz}$, a series of discrete frequency points are selected, through the type (13), and the mean square root of acceleration can be calculated.

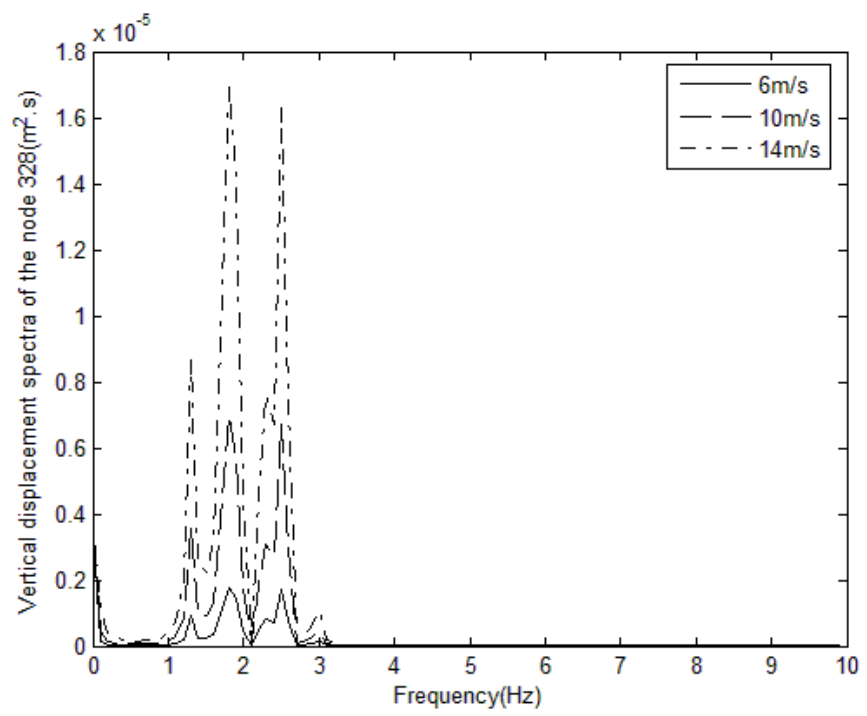

Fig. (5). Vertical displacement spectra of node 328.

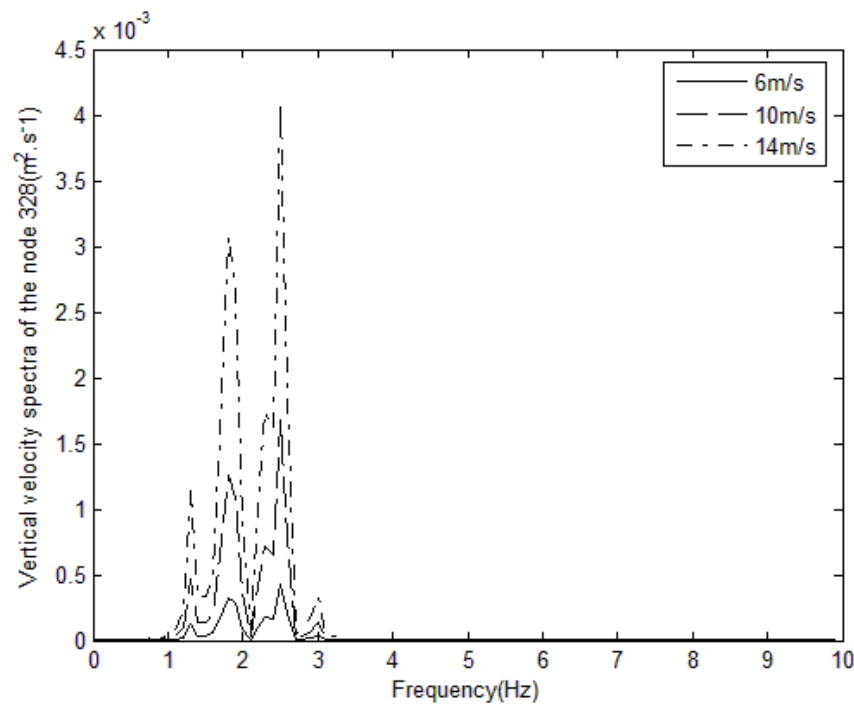

Fig. (6). Vertical velocity spectra of node 328 . $\sigma_{1 / 3}=\sqrt{\int_{0.89 f_{r}}^{1.12 f_{r}} S_{z z} d \omega}$

Tables 2 and 3 list the horizontal and vertical $1 / 3$ frequency multiplication acceleration root mean squares in the location of operation room node 157. According to the international standard ISO 2631 body fatigue/efficiency lower limit, the acceleration root mean square of the type of tower crane is standard 8 hours working efficiency under the lower limit, which can ensure that the workers are not influenced by the wind vibration in the working time [11].

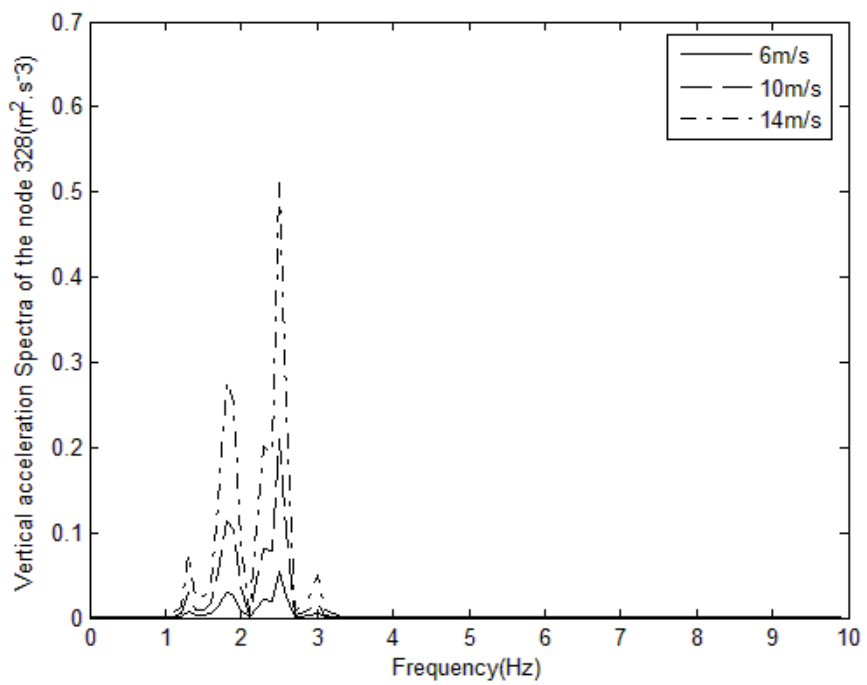

Fig. (7). Vertical acceleration spectra of node 328.

\section{CONCLUSION}

With the complex characteristics of the tower crane under random dynamic wind load, the traditional design can not reflect its dynamic response accurately. In the study, the finite element method and pseudo-excitation method were adopted in the wind induced vibration response analysis of the tower crane. It can accurately reflect the operation arm vibration response caused by a fluctuating wind load and can also improve the efficiency of computing. It can provide a feasible way for wind induced vibration analysis of a working truck.

Through the analysis of the level, vertical displacement, velocity and acceleration of the power spectrum of the tower

Table 2. One-third Octave acceleration RMS (horizontal).

\begin{tabular}{|c|c|c|c|c|c|c|c|c|c|c|}
\hline Mid-Frequency of Octave Band/Hz & 1 & 1.5 & 2 & 2.5 & 3 & 4 & 5 & 6 & 8 & 10 \\
\hline$\sigma_{1 / 3} /\left(m \cdot s^{-1}\right)$ & 0.05 & 0.17 & 0.32 & 0.45 & 0.23 & 0.103 & 0.068 & 0.024 & 0.017 & 0.01 \\
\hline
\end{tabular}

Table 3. One-third Octave acceleration RMS (Vertical).

\begin{tabular}{|c|c|c|c|c|c|c|c|c|c|c|}
\hline Mid-Frequency of Octave Band/Hz & 1 & 1.5 & 2 & 2.5 & 3 & 4 & 5 & 6 & 8 & 10 \\
\hline$\sigma_{1 / 3} /\left(m \cdot s^{-1}\right)$ & 0.15 & 0.22 & 0.45 & 0.63 & 0.29 & 0.23 & 0.17 & 0.07 & 0.04 & 0.03 \\
\hline
\end{tabular}


arms, it was observed that the main response frequency is between 1 and $3 \mathrm{~Hz}$. Vibration response is obvious and the influence of the wind speed on the vibration is large as the amplitude obviously increased with the increase in wind speed.

One third acceleration mean square root of the tower arm at each frequency point is below the international body fatigue/efficiency standards of ISO2631, and it has no significant effect on the workers.

\section{CONFLICT OF INTEREST}

The authors confirm that this article content has no conflict of interest.

\section{ACKNOWLEDGEMENTS}

Declared none.

\section{REFERENCES}

[1] D.K. Sun, J.H. Lin, and Y.H. Zhang, "The wind induced random vibration analysis of complex structures", Journal of Mechanical Engineering, vol. 5, pp. 55-61, 2001.

[2] Y.L. Xu, W.S. Zhang, and J.M. Ko, "Pseudo - excitation method for vibration analysis of wind - Excited structures", Journal of
Wind Engineering and Industrial Aero Dynamics, vol. 83, pp. 443-454, 1999.

[3] W.T. Xu, J.H. Lin, and Y.H.Z hang, "2D moving method for random vibration analysis of of vehicles on Kirchhoff plate with Kelvin foundation", Journal of Latin America -- Solid and Structures, vol. 6, pp. 169-183, 2009.

[4] F.L. Wang, W. Gao, and J.J. Chen, "Prescribed by ritual law incentive antenna structure under random vibration analysis", Journal of Engineering Mechanics, vol. 23, pp. 168-172, 2006.

[5] J.H Lin, and Y.H. Zhang, Random vibration of the pseudoexcitation method. Beijing: Science Press, pp.42-44, 2004.

[6] Z.Y. Sun, and H. Wang, "Structural random vibration analysis of equivalent excitation method", Journal of Engineering Mechanics, vol. 27 , pp. 20-23, 2010 .

[7] W.D. Wang, L.N. Sun, and Z.J. Du, "Move the arm vibration analysis based on pseudo-excitation method", Journal of Jilin University, vol. 40, pp.1082-1085, 2010.

[8] G.X. Bu, P. Tan, and Y. Zhang, "Large random wind vibration response of tall building analysis", Journal of Harbin Institute of Technology, vol. 42, pp. 175-179, 2010.

[9] J.R. Sun, and C.S. Xu, "Marine deck crane boom structure wind vibration response study", Journal of Lifting the Transport Machinery, vol. 12, pp. 20-23, 2009.

[10] S.H. Wang, S.J. Song, and T.H. Tong, "Modal analysis of a tower crane structure", Journal of Mechanical Science and Technology for Aerospace Engineering, vol. 29, pp. 912-914, 2010.

[11] L.X. Li, and G.Q. Song, "Based on ANSYS, the analysis of the effect of natural vibration characteristics of passenger train", Journal of Vibration and Shock, vol. 30, pp. 121-123, 2011.

This is an open access article licensed under the terms of the Creative Commons Attribution Non-Commercial License (http://creativecommons.org/licenses/ by-nc/4.0/) which permits unrestricted, non-commercial use, distribution and reproduction in any medium, provided the work is properly cited. 